Don't ask, don't tell, don't publish

I n 1993, Dean Hamer and colleagues at the NIH caused a minor sensation when they published a paper in Science, reporting a genetic association between homosexual orientation among American males and a locus on chromosome Xq28. The popular press immediately seized on the report: the 'gay gene' had been found.

The paper provoked a flood of comment and controversy. Many biologists were highly sceptical that behaviour as complex as sexual preference could possibly be specified by a single genetic locus. Evolutionary theorists found it hard to accept that a genetic trait with such an obviously negative influence on reproductive success could possibly become established within the population. Those more inclined to genetic determinism flaunted their satisfaction.

Many of the reactions to the publication were of a less scientific nature. Religious zealots condemned the idea that homosexuality could be considered as anything other than a sin, subject to divine judgement. 'Violators' who wish to avert hellfire should turn not to genetics, but to prayer, abstinence and faith-based 'therapy'. In contrast, gay rights activists mostly welcomed the finding that homosexuality was, after all, biologically innate and immutable, rather than a moral choice to be argued over. Being gay was no longer anyone's 'fault', except, perhaps, as some wryly observed, that of their mothers, for unwittingly passing on a variant $X$-chromosome.

Others were a little more queasy at the implications. If homosexuality were governed by a single gene, then it could also be revealed on the basis of a simple DNA test. Not only might this invade the privacy of those who preferred to keep their sexual preferences a personal matter, it also offered the chilling prospect that future parents might choose to avoid having homosexual children altogether, as a result of pre-implantation genetic testing, or via termination. Those who had fought to establish full civil rights for gays were witnessing the emergence of knowledge that might once again allow homosexuality to be portrayed as a disease rather than a difference. Similar fears have accompanied the identification of the genetic factors that underlie congenital deafness. Although, in theory, this could allow deaf parents to exercise the choice of having a child who was also deaf, many in the deaf community are more troubled by the greater likelihood that it will lead to the marginalization and eventual elimination of their cultural identity.

Following the initial publication of Hamer's findings, other investigators were unable to replicate them, casting doubt on the whole concept. Hamer's own later work found a much weaker association between homosexuality and chromosome Xq28, although several other loci in the genome appeared to show robust associations, even if none of them contributed more than a quantitatively small fraction of the overall trait. There the matter has rested for most of the intervening years: a not untypical genetic controversy that risks sullying the reputations of those embroiled in it, compounded by the societal pressures that swirl about the whole topic. Most scientists have understandably chosen simply to avoid the subject.

One might also question the wisdom of society investing significant funding into researching the underlying biology of what has, indeed come to be regarded as a valid alternative lifestyle, and thus not at all relevant to health as such. If gays aren't sick, aren't we all far better off putting scarce resources into studying the causes of real diseases, which cause so much suffering?

A useful comparison can be made with the biology of prostate cancer, a deadly disease that impacts the lives of perhaps ten times as many men as are attracted to their own sex. Curiously, both homosexual orientation and prostate cancer exhibit a high degree of heritability. Genetic studies of prostate cancer, like those of homosexuality, are plagued with ascertainment issues, mainly due to the high prevalence and late onset of the disease. Indeed, prostate cancer is the most heritable of all common cancers, even though, like male homosexuality, it appears to be a highly polygenic trait. The failure to find a single, prevalent prostate cancer gene has been a major handicap for the field, compared, for example, with breast cancer research. Even some of the loci that have been clearly identified as predisposing to prostate cancer do not appear to be conventional genes at all. Some delineate regulatory sequences or non-coding RNAs, whose mode of action remains obscure. The remainder implicate a plethora of biological pathways that currently do not resolve to a simple mechanistic hypothesis, and require much further research eventually to produce a viable therapy. Research into the genetic basis of male homosexuality could end up as a similarly frustrating, lengthy and costly undertaking.

For all these reasons, only a tiny dribble of funding, generating a paltry handful of mainly inconsequential publications, is currently dedicated to research on the genetics of homosexuality. But even without invoking the social necessity of providing an avenue to personal fulfilment of the tens of millions of spare males in Asia, I believe the topic is as worthy of study as any in basic biology. The purpose of research is not simply to alleviate suffering. It is also a quest to understand ourselves and the world in which we live. Hopefully, the emerging social enlightenment that enables us to classify sexual preference as a morally neutral attribute will, in time, embolden molecular biologists to return to it.

\section{Howy Jacobs}

EMBO reports (2012) 13, 393; doi:10.1038/embor.2012.48 